\title{
Esporotricose felina: um relato de caso de disseminação cutânea e sistêmica em gato negativo para FIV e FeLV*
}

\section{Feline sporotrichosis: a case report of cutaneous and systemic dissemination in cat negative for FIV and FeLV}

\author{
Francine dos Santos da Silva, ${ }^{* *}$ Simone Carvalho dos Santos Cunha, ${ }^{* * *}$ Vanessa Araujo de Moraes, ${ }^{* * *}$ \\ Juliana da Silva Leite, ${ }^{* * * *}$ Ana Maria Reis Ferreira****
}

\begin{abstract}
Resumo
A esporotricose é uma zoonose causada por fungos do gênero Sporothrix. Os gatos doentes têm importante potencial zoonótico e frequentemente revelam uma apresentação disseminada da doença. O objetivo deste relato de caso é descrever as características clínicas e anatomopatológicas de um caso de esporotricose felina refratária ao tratamento com apresentação clínica cutânea disseminada e sistêmica. Um felino macho de 3 anos de idade foi tratado para esporotricose com itraconazol e obteve resolução completa das lesões cutâneas. Porém, um ano após alta clínica, o animal apresentou aumento e ulceração da região nasal. Após cultura fúngica positiva para Sporothrix spp foi instituído tratamento com itraconazol 100mg associado ao iodeto de potássio $20 \mathrm{mg}$ por via oral diariamente e transcorrido 3 meses de tratamento, foi observada piora progressiva do sinais clínicos com disseminação de lesões para outras regiões do corpo. O animal foi submetido à eutanásia e encaminhado para necrópsia no Serviço de Anatomia Patológica da Faculdade de Veterinária da Universidade Federal Fluminense. Amostras da língua, pulmão, fígado, baço, rim, cérebro, linfonodo e pele foram coletadas para evidência de disseminação do agente fúngico e avaliação de alterações microscópicas. A coloração de metenamina de prata de Grocott foi utilizada para facilitar a visualização de leveduras sugestivas de Sporothrix spp nos cortes histológicos. Leveduras foram visualizadas em amostras de pele, língua, linfonodo, rim, fígado, baço e cérebro. No presente relato a disseminação do Sporothrix spp para diversos órgãos sinaliza a necessidade de uma minuciosa investigação dos casos graves de esporotricose felina para o tratamento adequado.
\end{abstract}

Palavras-chave: esporotricose sistêmica, gato, necropsia, zoonose.

\begin{abstract}
Sporotrichosis is a zoonosis caused by fungi of the genus Sporothrix. Sick cats have an significant zoonotic potential and often show a widespread presentation of the disease. The purpose of this case report is to describe the clinical and anatomopathological characteristics of a case of feline sporotrichosis refractory to treatment with disseminated and systemic cutaneous clinical presentation. A 3-year-old male feline was treated for sporotrichosis with itraconazole and achieved complete resolution of the skin lesions. However, one year after clinical discharge, the animal presented an increase and ulceration of the nasal region. After a positive fungal culture for Sporothrix spp, treatment with itraconazole 100mg associated with potassium iodide $20 \mathrm{mg}$ was instituted orally daily and after 3 months of treatment, a progressive worsening of the symptoms was observed with the spread of lesions to other regions of the body. The animal was euthanized and sent for necropsy at the Pathological Anatomy Service of the Veterinary Faculty of Universidade Federal Fluminense. Samples of the tongue, lung, liver, spleen, kidney, brain, lymph node, and skin were collected for evidence of spread of the fungal agent and evaluation of microscopic changes. Grocott silver methenamine staining was used to facilitate the visualization of yeasts suggestive of Sporothrix spp in histological sections. Yeasts were visualized in samples of skin, tongue, lymph node, kidney, liver, spleen, and brain. In the present report, the spread of Sporothrix spp to different organs signals the need for a thorough investigation of severe cases of feline sporotrichosis for the proper treatment.
\end{abstract}

Keywords: systemic sporotrichosis, cat, necropsy, zoonosis.

\section{Introdução}

A esporotricose é uma infecção fúngica causada por espécies termodimórficas do gênero Sporothrix (BAZZI et al., 2016). Várias espécies de Sporothrix foram isolados de lesões felinas ou humanas e, nas últimas duas décadas, o ramo clonal altamente virulento $S$. brasiliensis tem sido associado a infecções em animais e humanos através de arranhões ou mordidas de gatos infectados (ALMEIDA-PAES et al., 2014; RODRIGUES; HOOG; CAMARGO, 2016). Atualmente a esporotricose é

*Recebido em 26 de outubro de 2020 e aceito em 28 de janeiro de 2021.

**Universidade Federal Fluminense, Faculdade de Veterinária, Programa de Pós-graduação Medicina Veterinária (Clínica e Reprodução Animal), Niterói, RJ, Brasil. Autor para correspondência: francinesilva@id.uff.br.

***Universidade Federal Fluminense, Faculdade de Veterinária, Programa de Pós-graduação Medicina Veterinária (Clínica e Reprodução Animal), Niterói, RJ, Brasil.

***Universidade Federal Fluminense, Faculdade de Veterinária, Departamento de Patologia e Clínica Veterinária, Niterói, RJ, Brasil. 
considerada hiperendêmica no Rio de Janeiro (GREMIÃO et al., 2020; RODRIGUES; HOOG; CAMARGO, 2016).

Os felinos com esporotricose, frequentemente, apresentam múltiplas lesões cutâneas com envolvimento das membranas mucosas do trato respiratório. Nódulos e úlceras são as lesões mais comuns e podem ser encontrados em três ou mais regiões anatômicas não-contíguas, geralmente na cabeça, especialmente na região nasal (GREMIÃO et al., 2015). A forma extracutânea pode comprometer diversas áreas do organismo com envolvimento dos pulmões, articulações, seios nasais ou sistema nervoso central (BARROS et al., 2011; BENTLEY; TAYLOR; THOMOVSKY, 2018). Sinais extracutâneos respiratórios (espirros, dispneia e secreção nasal), assim como linfangite e linfadenomegalia podem estar presentes (GREMIÃO et al., 2015).

$O$ diagnóstico definitivo da esporotricose requer o isolamento do fungo em meio de cultura e posterior identificação, que pode demorar cerca de 20 dias (BARROS, 2011; SCHUBACH et al., 2002). Nos gatos, os exames citopatológico e histopatológico são úteis pela rapidez no diagnóstico. Essas ferramentas diagnósticas são importantes em casos em que o cultivo do Sporothrix spp foi prejudicado, como observado nos animais com lesões crônicas e/ou em tratamento de longo prazo com antifúngicos e baixa carga fúngica (BAZZI, et al 2016; PEREIRA et al., 2011; SILVA et al., 2018).

O tratamento da esporotricose felina pode ser de longo prazo dependendo da gravidade e dos locais das lesões (GREMIÃO et al., 2017). O Cetoconazol na dosagem 5 a $10 \mathrm{mg} / \mathrm{kg}$ SID ou BID (SCHUBACH, et al., 2004) pode ser usado. Embora o itraconazol seja o fármaco de eleição com boa atividade in vitro contra cepas de S. brasiliensis (BRILHANTE et al., 2015). GREMIÃO et al., 2020b recomenda o uso de itraconazol em cápsulas nas doses $100 \mathrm{mg}$ a cada $24 \mathrm{horas}$ (gatos $\geq 3 \mathrm{~kg}$ ); $50 \mathrm{mg}$ a cada 24 horas (gatos $\geq 1 \mathrm{~kg} \mathrm{e}<3 \mathrm{~kg}$ ) e $25 \mathrm{mg} / \mathrm{kg}$ a cada 24 horas (gatos $<1 \mathrm{~kg}$ ). Itraconazol associado à cápsula de iodeto de potássio na dosagem $(2,5-5 \mathrm{mg} / \mathrm{kg}$ a cada 24 hora) é recomendado para casos refratários a monoterapia com itraconazol. Anfotericina B administrada por via subcutânea ou intralesional associada ao itraconazol oral é uma alternativa para casos refratários aos antifúngicos azólicos (GREMIÃO, 2011).

\section{Relato de caso}

Um felino, macho, sem raça definida, 3 anos de idade e 5 quilos, resgatado da rua no município de Niterói um ano antes, atualmente domiciliado, foi atendido em consulta clínica apresentando lesão nasal ulcerada. $\mathrm{O}$ animal, quando resgatado, teve diagnóstico citopatológico de infecção por Sporothrix spp., e foi tratado com itraconazol $100 \mathrm{mg} /$ gato ao dia por via oral, durante 2 meses. À época, houve cura clínica da lesão na região nasal com epitelização total e ausência de exsudato, crostas, eritema ou descamação. Porém, após um ano da alta clínica, o animal apresentou rápido crescimento da lesão cicatricial da região nasal progredindo para formação de lesão tumoral ulcerada e disseminação das lesões para as regiões auriculares e perioculares. No momento do atendimento, o animal apresentava normofagia, normodpsia, espirros e dispneia, e no exame clínico apresentava mucosas normocoradas, linfoadenomegalia mandibular bilateral, temperatura retal $38,3^{\circ} \mathrm{C}$, lesão nodular ulcerada em região nasal e nódulos nas regiões perioculares e pavilhões auriculares (Figura 1).
Figura 1: Lesão tumoral ulcerada em região nasal, lesões nodulares em regiões perioculares e auriculares em felino com esporotricose disseminada

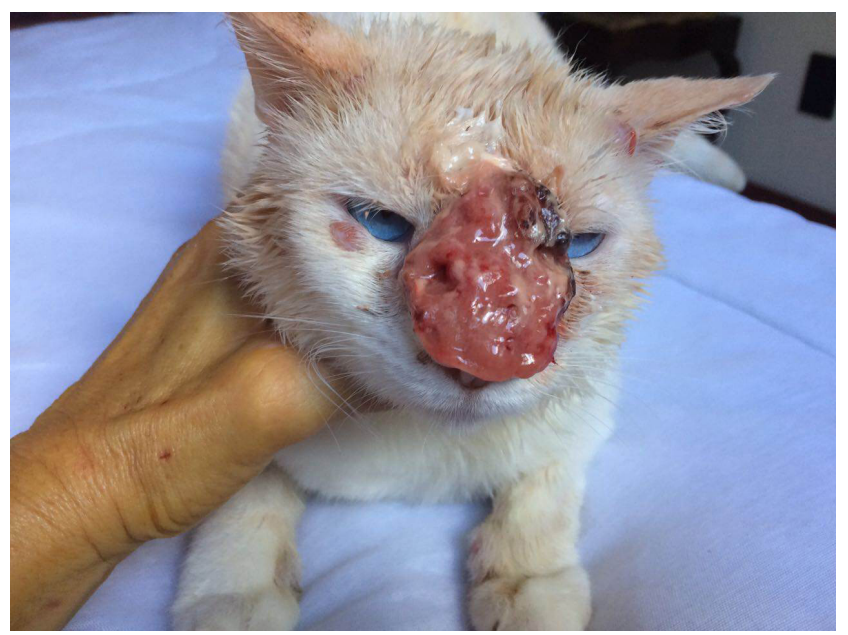

O exame citopalógico coletado por imprint em lâmina de microscopia e a amostra corada pelo método panóptico rápido evidenciou estruturas fúngicas compatíveis com Sporothrix spp. A partir de coleta de exsudato da lesão ulcerada do plano nasal por meio de um swab estéril, foram realizados cultura fúngica e isolamento de Sporothrix spp. O isolamento do Sporothrix spp foi realizado em meio ágar Sabouraud dextrose e ágar Micosel a $25^{\circ} \mathrm{C}$ e em seguida o agente foi semeado em meio $\mathrm{BHI}$ a $37^{\circ} \mathrm{C}$ para a prova de dimorfismo térmico. Foi procedida a colheita de sangue total para realização de hemograma completo, bioquímica sérica (Alanina aminotransferase, Fosfatase Alcalina, Uréia e Creatinina) e teste rápido para detecção de anticorpos do FIV e antígenos do FeLV (ELISA, SNAP ${ }^{\circledR}$ Combo Plus, IDEXX). As alterações hematológicas foram discretas: anisocitose e policromasia, moderada presença de rouleaux eritrocitário, trombocitopenia e hiperproteinemia. A bioquímica renal e a hepática apresentavam-se dentro dos valores de normalidade e o teste rápido para detecção de anticorpos contra FIV e FELV mostrou resultado negativo.

O tratamento oral foi instituído com itraconazol $100 \mathrm{mg} /$ gato, iodeto de potássio na dosagem $4 \mathrm{mg} / \mathrm{kg}$ e S-adenosil-metionina (SAMe) na dosagem $20 \mathrm{mg} / \mathrm{kg}$, por via oral, SID. Devido à ausência de remissão dos sinais clínicos, e até mesmo piora após 30 dias de tratamento, foi feita tentativa de aumento da dose do iodeto de potássio para $5 \mathrm{mg} / \mathrm{kg} \mathrm{SID}$, porém o animal apresentou vômitos e anorexia. Após um total de 3 meses de tratamento, e sem melhora clínica das lesões, o felino apresentou prostração intensa, anorexia, vômitos, perda de peso, desidratação, febre, linfoadenomegalia, claudicação e disseminação das lesões para várias regiões do corpo incluindo membros.

O animal foi submetido à eutanásia e encaminhado para necropsia no Serviço de Anatomia Patológica Doutor Jefferson Andrade dos Santos da Faculdade de Veterinária da Universidade Federal Fluminense. A área ulcerada e exsudativa na região nasal media aproximadamente $6,0 \mathrm{~cm}$ de diâmetro e as lesões cutâneas dos membros variavam de 1,5 a $2,5 \mathrm{~cm}$ de diâmetro. Estas lesões apresentavam região central ulcerada, expondo a camada muscular e nervos, e bordos elevados, pálidos e 
edemaciados. Observou-se ainda que na porção apical da língua havia um nódulo milimétrico, arredondado, circunscrito, com coloração creme e superfície integra e linfonodos mandibulares bilaterais estavam aumentados. Os órgãos das cavidades torácica e abdominal foram examinados macroscopicamente e não apresentavam alterações. Amostras de língua, pulmão, fígado, baço, rim, cérebro, linfonodo e pele foram coletadas para comprovação de disseminação do agente fúngico e avaliação das alterações microscópicas. Os materiais foram fixados em formalina a $10 \%$, processadas de acordo com as técnicas histológicas de rotina e coradas pela hematoxilinaeosina (HE) e Grocott (GMS)

A avaliação histopatológica da pele coradas pelo HE revelou reação piogranulomatosa com intensa quantidade de estruturas leveduriformes, variando de oval á alongada, e que mediam de 2 a $8 \mu \mathrm{m}$. No interior de macrófagos e neutrófilos, as leveduras estavam, em sua maioria, acompanhadas por infiltrado inflamatório moderado de neutrófilos, macrófagos e linfócitos e a lesão se estendia da epiderme à camada muscular (Figura 2).
$\mathrm{Na}$ língua, observou-se acentuada quantidade de estruturas leveduriformes com discreto infiltrado inflamatório misto focal. Nos cortes histológicos dos linfonodos havia intensa infiltração pelos macrófagos contendo numerosas estruturas leveduriformes. Moderada degeneração das células tubulares, aumento do espaço de Bowman, leve perda glomerular, presença de pigmento acastanhado e áreas de fibrose com infiltrado inflamatório com leveduras foram observados em tecido renal. O fígado apresentava degenerações micro ou macromaculares, moderada dissociação multifocal dos hepatócitos e leveduras e infiltrado inflamatório periportal leve. No baço, foram observadas leveduras, grande quantidade de pigmento de hemossiderina e moderada congestão. Raras estruturas em forma de leveduras foram observadas no cérebro. Não foram observadas alterações em pulmão.

A técnica de impregnação pela prata de Grocott (GMS) foi utilizada para facilitar a visualização e caracterização de estruturas leveduriformes sugestivas de Sporothrix nos cortes histológicos (Figura 3).

Figura 3: Esporotricose extracutânea em felino. Linfonodo (A), Rim (B), Fígado (C) e Cérebro (D) - presença de estruturas arredondadas e esporuladas compatíveis com leveduras (setas) coradas em cinza (GROCOTT).

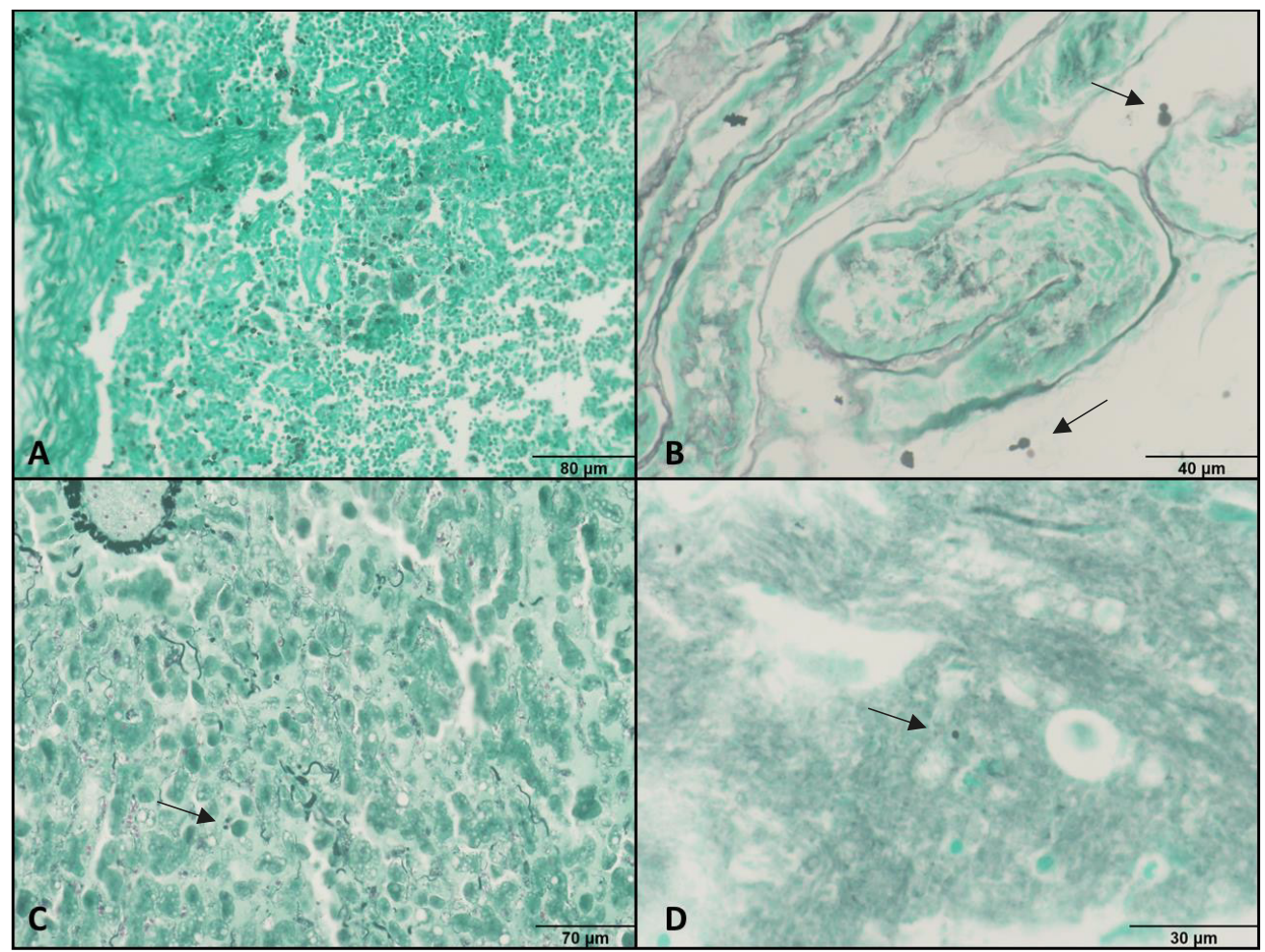


A observação através da objetiva de imersão (aumento de 1000x) de leveduras arredondadas, em forma de charuto, ou em forma de clava, marrom-acinzentadas, com ou sem brotamento foram evidenciadas em pele, língua, linfonodo, rim, fígado, baço e cérebro.

\section{Discussão}

Este trabalho relata o caso de um felino que, após tratamento e cura clínica de lesão nasal, apresentou recidiva da esporotricose e evolução para uma disseminação cutânea e sistêmica.

O retorno da lesão no mesmo local da cicatriz nasal indica recidiva da doença que, posteriormente, evoluiu para uma disseminação cutânea e sistêmica. A doença sistêmica revelou envolvimento de múltiplos órgãos como pele, língua, linfonodos, baço, fígado, rim e cérebro, mesmo sob tratamento antifúngico. Estudos relatam que em alguns gatos, apesar do tratamento regular e prolongado, pode haver a ativação de lesões cutâneas, em locais de mesma localização entre três e 18 meses após o final do tratamento com cura clínica. Formas viáveis de Sporothrix spp podem ficar sequestradas nos tecidos por seis meses sem ocasionar sinais clínicos e lesões aparentemente cicatrizadas podem ser reativadas (SCHUBACH et al., 2004). A ocorrência de esporotricose felina refratária é alta, principalmente, na região nasal (PEREIRA, 2011).

No caso mencionado foram observados placas, nódulos e ulcerações em regiões da orelha, membros, dorso e cauda, mesmo após longo tratamento com associação de Itraconazol $100 \mathrm{mg}$ e lodeto de potássio $20 \mathrm{mg}$ SID. Estudo sobre o tratamento da esporotricose felina refratária ao itraconazol relatou $13,1 \%$ de falência medicamentosa em gatos tratados com iodeto de potássio em cápsulas via oral $(5 \mathrm{mg} / \mathrm{kg}$ a cada 24 horas) associado ao itraconazol via oral $(100 \mathrm{mg} / \mathrm{gato}$ a cada 24 horas) (ROCHA et al., 2018). A ocorrência de reações adversas ao medicamento (anorexia, diarréia e vômito) foi alta em estudo com 26 gatos tratados com iodeto de potássio na dosagem (10mg/kg duas vezes ao dia) (CARVALHO et al., 2018). Autores relataram a dificuldade no tratamento das lesões nasais em felinos com esporotricose e que apesar da implementação de monoterapia com itraconazol ou a combinação deste com anfotericina B intralesional foram observadas evolução das lesões e a presença de elementos fúngicos no exame histopatológico (GREMIÃO et al., 2011).

Anemia, leucocitose com neutrofilia, hipoalbuminemia e hiperglobulinemia são os achados hematológicos mais frequentes na esporotricose felina (SCHUBACH et al., 2004). No presente caso, o felino não apresentava alteração na contagem de leucócitos, e sim discreta anisocitose e policromasia, moderada presença de rouleaux eritrocitário, trombocitopenia e hiperproteinemia. Sorologia (método ELISA) FIV/FELV foi realizada com resultado negativo. Em gatos a correlação entre a severidade da esporotricose e co-infecção com o vírus da imunodeficiência felina (FIV) ou vírus da leucemia felina (FeLV) ainda não é estabelecida e, frequentemente, felinos com casos severos são aparentemente imunocompetentes (GREMIÃO et al., 2020; MIRANDA et al., 2013). Acredita-se que a imunidade mediada por células desempenhe um papel importante no controle da esporotricose felina, já que o aumento das porcentagens de células CD4 está correlacionado com lesões únicas, inflamação bem organizadas e menor carga fúngica (MIRANDA et al., 2016).

A avaliação histopatológica da pele com coloração HE revelou reação granulomatosa supurativa, com presença de granulomas mal organizados e intensa presença de leveduras no interior de macrófagos ativados, semelhante ao descrito por diversos autores (BAZZI et al., 2016; MONTEIRO DE MIRANDA et al., 2009; SCHUBACH et al., 2004). Por meio de coloração especial pela prata de Grocott foram identificadas leveduras redondas, ovaladas em pele, língua, linfonodo, rim, baço, fígado e cérebro. A utilização de colorações especiais, como a impregnação pela prata de Grocott (GMS) e ácido periódico de Schiff (PAS), são ferramentas utilizadas para facilitar a visualização e caracterização do agente evidenciando-se leveduras em cinza escuro no GMS e rosadas no PAS (BAZZI et al., 2016). Um estudo apontou o $S$. brasiliensis sendo o membro mais virulento do clado patogênico do gênero Sporothrix e demonstrou que isolados altamente virulentos podem disseminar da pele para fígado, baço, rins, pulmões, coração e cérebro de animais infectados, induzindo a perda de peso crônica (TERRA et al., 2017). O presente estudo não determinou a espécie de Sporothrix envolvida, porém o Rio de Janeiro é uma região hiperendêmica que apresenta alta prevalência de infecções por S. brasiliensis (GREMIÃO et al., 2017) e pela apresentação grave e disseminada juntamente com a refratariedade ao tratamento, suponhamos que seja uma cepa virulenta.

A disseminação sistêmica e comprometimento de órgãos como pulmões, fígado, baço, linfonodos e cérebro é um fator complicador no tratamento da esporotricose felina. $O$ itraconazol pode ser eficaz no tratamento de infecções fúngicas no SNC, é altamente lipofílico e atinge altas concentrações nos tecidos, embora casos refratários têm sido descritos (ROCHA et al., 2018). O fluconazol é mais comumente utilizado no tratamento de meningoencefalites fúngicas de pequenos animais, por ter mostrado maior concentração no líquido cefalorraquidiano (LCR), porém existem poucos relatos sobre a sua utilização na esporotricose felina e sua segurança e eficácia ainda precisa ser estabelecida (GREMIÃO et al., 2020). $A$ anfotericina $B$ é utilizada com frequência no tratamento das infecções fúngicas sistêmicas em humanos, contudo esse medicamento é fracamente absorvido no tecido nervoso de cães e gatos, e nos casos da esporotricose felina, esse medicamento é utilizado SC ou intralesional (NEVES; TUDURY, 2010; GREMIÃO et al., 2009).

\section{Conclusão}

O felino deste relato apresentou manifestações clínicas polimórficas da esporotricose, com disseminação para vários órgãos. Portanto, é necessário alertar sobre a ocorrência do envolvimento sistêmico dessa doença crônica causada por Sporothrix spp. e a importância da adequada escolha do medicamento, duração do tratamento e acompanhamento não só das lesões cutâneas para correta avaliação da cura clínica em áreas endêmicas.

Financiamento: FAPERJ (Fundação de Amparo à Pesquisa do Estado do Rio de Janeiro).

Declaração de interesse: Os autores informam que não há conflitos de interesse. Os autores são os únicos responsáveis pelo conteúdo e redação do artigo. 


\section{Referencias}

ALMEIDA-PAES, R. et al. Sporotrichosis in Rio de Janeiro, Brazil: Sporothrix brasiliensis Is Associated with Atypical Clinical Presentations. PLOS Neglected Tropical Diseases, v. 8, n. 9, p. e3094, 18 set. 2014.

BARROS, M. B. DE L.; DE ALMEIDA PAES, R.; SCHUBACH, A. O. Sporothrix schenckii and Sporotrichosis. Clinical Microbiology Reviews, v. 24, n. 4, p. 633-654, out. 2011.

BAZZI, T. et al. Características clínico-epidemiológicas, histomorfológicas e histoquímicas da esporotricose felina. Pesquisa Veterinária Brasileira, v. 36, n. 4, p. 303-311, abr. 2016.

BENTLEY, R. T.; TAYLOR, A. R.; THOMOVSKY, S. A. Fungal Infections of the Central Nervous System in Small Animals: Clinical Features, Diagnosis, and Management. Veterinary Clinics: Small Animal Practice, v. 48, n. 1, p. 63-83, 1 jan. 2018.

BRILHANTE, R. S. N. et al. In vitro inhibitory activity of terpenic derivatives against clinical and environmental strains of the Sporothrix schenkii complex. Medical Mycology, v. 53, n. 2, p. 93-98, 1 fev. 2015.

CARVALHO, B. W. et al. lodeto de sódio: uma alternativa de tratamento para a esporotricose felina?.Acta Scientiae Veterinariae, v. 46, p. 1618, 2018.

GREMIÃO, I. D. F. et al. Intralesional amphotericin B in a cat with refractory localised sporotrichosis. Journal of Feline Medicine and Surgery, v. 11, n. 8, p. 720-723, ago. 2009.

GREMIÃO, I. et al. Treatment of refractory feline sporotrichosis with a combination of intralesional amphotericin $\mathrm{B}$ and oral itraconazole. Australian Veterinary Journal, v. 89, n. 9, p. 346351, set. 2011.

GREMIÃO, I. D. F. et al. Feline sporotrichosis: epidemiological and clinical aspects. Medical Mycology, v. 53, n. 1, p. 15-21, 1 jan. 2015.

GREMIÃO, I. D. F. et al. Zoonotic Epidemic of Sporotrichosis: Cat to Human Transmission. PLOS Pathogens, v. 13, n. 1, p. e1006077, 19 jan. 2017.

GREMIÃO, I. D. F. et al. Guideline for the management of feline sporotrichosis caused by Sporothrix brasiliensis and literature revision. Brazilian Journal of Microbiology: [publication of the Brazilian Society for Microbiology], 29 set. 2020.
MIRANDA, L. H. M. et al. Feline sporotrichosis: histopathological profile of cutaneous lesions and their correlation with clinical presentation. Comparative Immunology, Microbiology and Infectious Diseases, v. 36, n. 4, p. 425-432, jul. 2013.

MIRANDA, L. H. M. et al. Severe feline sporotrichosis associated with an increased population of CD8 low cells and a decrease in CD4 + cells. Medical Mycology, v. 54, n. 1, p. 29-39, 1 jan. 2016.

MONTEIRO DE MIRANDA, L. et al. Histopathology of Canine Sporotrichosis: A Morphological Study of 86 Cases from Rio de Janeiro (2001-2007). Mycopathologia, v. 168, p. 79-87, 1 ago. 2009.

NEVES, I. V.; TUDURY, E. A. Fármacos utilizados no tratamento das afecções neurológicas de cães e gatos Medical treatment of neurologic diseases of dogs and cats. E. A., v. 31, n. 3, p. 23, 2010.

PEREIRA, S.A.; PASSOS, S.R.; SILVA, J.N.; GREMIAO, I.D.; FIGUEIREDO, F.B.; TEIXEIRA, J.L. Response to azolic antifungal agents for treating feline sporotrichosis. Vet Rec, v.166(10), p. 290-4, 2010.

ROCHA, R. F. D. B. DA et al. Refractory feline sporotrichosis treated with itraconazole combined with potassium iodide. Journal of Small Animal Practice, v. 59, n. 11, p. 720-721, 2018.

RODRIGUES, A. M.; HOOG, G. S. DE; CAMARGO, Z. P. DE. Sporothrix Species Causing Outbreaks in Animals and Humans Driven by Animal-Animal Transmission. PLOS Pathogens, v. 12, n. 7, p. e1005638, 14 jul. 2016.

SCHUBACH, T. M. P. et al. Sporothrix schenckii isolated from domestic cats with and without sporotrichosis in Rio de Janeiro, Brazil. Mycopathologia, v. 153, n. 2, p. 83-86, 2002.

SCHUBACH, T. M. P. et al. Evaluation of an epidemic of sporotrichosis in cats: 347 cases (1998-2001). Journal of the American Veterinary Medical Association, v. 224, n. 10, p. 1623-1629, 15 maio 2004.

SILVA, J. N. et al. Comparison of the Sensitivity of Three Methods for the Early Diagnosis of Sporotrichosis in Cats. Journal of Comparative Pathology, v. 160, p. 72-78, abr. 2018.

TERRA, P. P. D. et al. Exploring virulence and immunogenicity in the emerging pathogen Sporothrix brasiliensis. PLOS Neglected Tropical Diseases, v. 11, n. 8, p. e0005903, 30 ago. 2017. 